\title{
Islamofobia Di Australia: Imigrasi, Integrasi Dan Terorisme Dari Perspektif Sejarah
}

Labibatussolihah, Wawan Darmawan, Nour Muhammad Adriani, Nurdiani Fathiraini Departemen Pendidikan Sejarah, FPIPS, Universitas Pendidikan Indonesia

Email: nour.adriani@upi.edu

\begin{abstract}
Abstrak: Sebagai negara bercorak Barat di kawasan Asia-Pasifik, pemerintah Australia mempromosikan semangat multikulturalisme yang mendorong kesetaraan di antara komunitas masyarakatnya termasuk antarumat beragama. Di sisi lain kampanye "war on terror" yang digagas Amerika Serikat pasca serangan 11 September juga berpengaruh pada persepsi masyarakat dunia yang melahirkan stigma "ketakutan terhadap Islam" atau Islamofobia termasuk di Australia. Melalui metode sejarah, telaah pustaka dilakukan untuk memunculkan alternatif sudut pandang Islamofobia di Australia secara historis. Dari perspektif ini ada beberapa hubungan yang dapat diambil, bahwa 1) kehadiran Islam di Australia meskipun sudah cukup lama tetapi belum berakar kuat secara historis; 2) persepsi orang Australia non-muslim terhadap Islam tidaklah buruk, namun terdapat sekelompok ekstrimis yang membenci Islam karena faktor citra negatif dan kebencian pribadi (personal dislike); 3) terdapat permasalahan integrasi masyarakat muslim di Australia salah satunya karena faktor perbedaan kultur asal muslim yang distigmatisasi secara umum; 4) penetrasi pemikiran radikal dikalangan umat Islam di Australia terjadi seperti halnya di masyarakat lain yang merasa tertindas atau termarginalkan.
\end{abstract}

\section{Kata Kunci: Islamofobia, war on terror, Australia, multikulturalisme}

Abstract: As a Western-culture country in the Asia-Pacific region, the Australian government promotes the spirit of multiculturalism that encourages equality, tolerance, and mutual respect among its communities, including among religious believers. On the other hand, the "war on terror" campaign initiated by the United States after the September 11 also affected the perception of the world community that trigger to the stigma of "fear of Islam" or Islamophobia. Through the historical method, we do a literature review to bring up an alternative viewpoint of Islamophobia in Australia form a historical perspective. There are a number of relations linked here, that 1) the presence of Islam in Australia although it has been quite a long time but has not been firmly rooted historically; 2) 'non-Muslim Australians' perceptions of Islam are not bad, but there are a group of extremists who hate Islam because of negative image factors and personal dislike; 3) there is a problem of integration of Muslim communities in Australia, one of which is due to differences in culture of Muslim origin and Islamic affiliation group among the community; 4) the infiltration of radicalism among Muslims in Australia occurs as in other communities who feel oppressed or marginalized

Keywords: Islamophobia, war on terror, Australia, multiculturalism.

\section{Pendahuluan}

Australia yang populer sebagai negeri yang beruntung (the lucky country) dikenal karena juga stabilitas politik dan keamanan dalam negerinya. Beberapa faktor yang mendukung hal tersebut adalah kekayaan alam yang melimpah, populasi yang kecil berbanding luasnya wilayah, serta posisi geografis yang jauh dari pusat- pusat aktivitas global. Kecilnya jumlah penduduk disadari merupakan ancaman bagi eksistensi kemakmuran negara sehingga sejak berdirinya federasi pada 1901, pemerintah selalu mengampanyekan kebijakan pro-imigran hingga hari ini. Hal itu juga berarti tantangan atas identitas nasional, tentang posisi sosio-kulturalnya di kancah regional (Blaxland, 2019). Situasi 
pasca berakhirnya White Australia Policy pada 1960-an menunjukan keterbukaan yang positif kepada cita-cita negara multikultur yang adil bagi semua meskipun diawali pertimbangan pragmatis "populate or perish" dari Billy Hughes pada 1937 (Edwards, 2018). Sejak tahun 1966 kehadiran bangsa-bangsa non-kulit putih di sambut, meski pemerintah juga dengan ketat membatasi jumlah maupun kualifikasi para imigran itu dalam rangka keseimbangan ekonomi dan demografis.

Dalam waktu yang cukup singkat, Australia menjadi masyarakat berbilang kaum yang terdiri dari komunitaskomunitas bangsa, bahasa, warna kulit, dan agama-agama, termasuk Islam (Edwards, 2018). Meskipun telah ada sejak masa prakolonial, kehidupan komunitas Muslim di Australia dalam abad ke-21 cenderung terstigmatisasi secara negative (Hersi, 2016).

Persepsi seperti tidak beradab (uncivilized), tidak berpendidikan (uneducated), dan kejam (violent) semakin kencang khususnya setelah peran aktif pemerintah dalam "war on terror" yang dikampanyekan Amerika Serikat pasca 11 September 2001 (Poynting \& Briskman, 2018). Keterlibatan pemerintah dan juga justifikasi mereka dalam keterlibatan ini seperti dalam perang Irak, mendorong efek prasangka terhadap Muslim menjadi semakin buruk dan penuh curiga. Sebaliknya, kalangan muslim merasa terpinggirkan dan dikucilkan dari masyarakat secara umum. Hal ini memunculkan ruang bagi ekstrimismeradikalisme di kedua belah pihak: kalangan anti-muslim yang kebanyakan juga antiimigran atau juga dikalangan Muslim garis keras (Edwards, 2018). Sebagian besar karya ilmiah terkait isu Islamofobia menekankan pada relasi Islam dan budaya muslim dengan prasangka negatif dan terorisme sehingga bersifat kontemporer (Briskman \& Latham, 2017; Ghauri, Yousaf, \& Iqbal, 2017; Hassan, 2015).

Kajian yang bersifat konteksual secara histioris sendiri belum banyak dilakukan apalagi yang menggunakan Bahasa Indonesia (Bazian, 2018; Roose \& Roose, 2016). Bagaimana fakta-fakta sejarah memandang isu Islamofobia di Australia? Apakah ada alternatif lain dalam menginterpretasi sejarah secara kontekstual dalam kasus Islamofobia di Australia khususnya relasi Islam dan masyarakat di sana secara umum?.

\section{Metode}

Studi menggunakan metode sejarah sebagai alat kerjanya meliputi tahapan heuristik, kritik sumber, interpretasi data, dan historiografi atau penulisan sejarah (Kuntowijoyo, 2005; Sjamsuddin, 2007). Dalam heuristik, dilakukan pengumpulan sumber-sumber meliputi sumber primer dan sumber sekunder. Sumber primer yang digunakan antara lain dokumen pemerintah 
dan pemberitaan sezaman. Adapun sumber sekunder terdiri dari jurnal-jurnal, tesis dan disertasi yang terbit sepuluh tahun terakhir dengan kata kunci: Islamofobia, multikulturalisme, dan radikalisme di Australia.

Sementara itu, studi kritik dilakukan secara terintegrasi dalam proses ini sebatas melihat kecenderungan (tendensi) kepengarangan dengan tidak berfokus pada orisinalitas karena sumber-sumber yang digunakan dianggap otoritatif. Interpretasi dilakukan secara kualitatif dengan memadukan data-data dalam sumber, menganalisis, dan menarik simpulan yang dapat dilihat dalam pembahasan berupa penulisan deskripsi atau historiografi (Sjamsuddin, 2007).

Pertimbangan personal seperti pengalaman pribadi penulis dan artikel di media masa digunakan untuk mendukung interpretasi itu dari reportase jurnalistik yang dianggap cukup represenatif dan relevan dengan rumusan masalah dan tujuan penulisan. Gaya penulisan atau historiografi yang disampaikan dalam jurnal ini merupakan deskripsi yang mendukung pada analisis pokok menuju simpulan.

\section{Hasil Dan Pembahasan}

\section{A. Kehadiran Islam di Australia}

Macassan. Kehadiran komunitas muslim pertama di Australia ditandai dengan penjelajahan orang-orang Nusantara, khususnya orang Makassar yang mencari komoditas laut, di sekitar Laut Arafura dan Celah Timor setidaknya sejak pertengahan abad ke-18 seiring meningkatnya permintaan trepang (sejenis timun laut) di Makassar (Macknight, 2013). Hubungan dagang terjadi antara para pelaut dengan warga Aborigin.

Dalam tradisi lisannya, orang-orang Makassar dikenang sebagai kaum musiman yang datang berkala untuk berdagang, kadang dengan kerja sama kaum pribumi di Dataran Arnhem untuk mencari trepang. Warisan kultural yang tersisa antara lain pengaruh bahasa dan sastra pada masyarakat Aborigin, suku Yolngu khususnya juga aspek kepercayaan (Islam) yang berbaur dalam animisme lokal (Ganter, 2013). Kehadiran orang-orang Makassar ini tidak meninggalkan komunitas muslim di sekitar pantai utara Australia.

Pada abad ke-19, orang-orang Inggris mulai membatasi kedatangan pelaut Makassar dengan menerapkan sistem cukai dan permit. Akhirnya pada 1907, pemerintah melarang sama sekali aktivitas dagang tersebut karena khawatir pengaruh mereka semakin kuat (Thomas, 2013). Siklus musiman orang-orang Makassar juga menyebabkan tidak adanya pemukiman permanen komunitas Muslim di sana, bahkan sekedar perkawinan campur dengan masyarakat Aborigin setempat (Ganter, 2013; Ross, 2000; Thomas, 2013). The Cameleers. Pada pertengahan abad ke-19, misi eksplorasi kawasan pedalaman 
Australia menjadi semangat pemerintah di wilayah barat dan utara. Mengadaptasi lingkungan, Burke dan Wills memimpin ekspedisi awal di wilayah selatan dengan memanfaatkan unta. Dengan asumsi bahwa unta-unta itu terikat pada majikannya, pemerintah mendatangkan juga para penunggang unta dari Asia Selatan yang dikenal sebagai the cameleers.

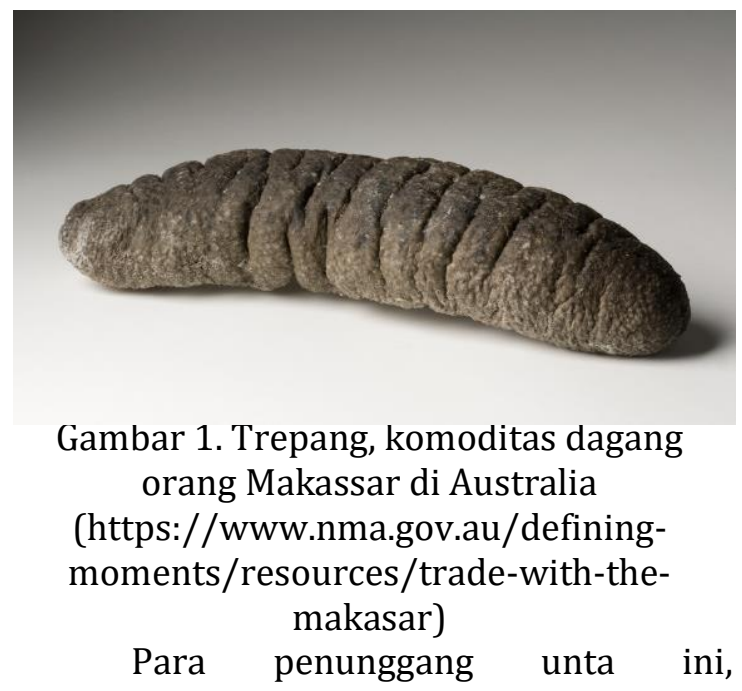

kebanyakan muslim Afghan dengan status pekerja kontrak. Setelah bertugas dalam misi ekspedisi atau penyaluran logistik ke permukiman di pedalaman selama 2-3 tahun sebagian besar kembali ke tempat asalnya. Dari 2000-lebih penunggang unta, hanya seratusan saja yang menetap di Australia, berkeluarga hingga meninggal (Jones, Kenny, \& Museum, 2010; Ross, 2000). Kehadiran warga Muslim Afghan ini, memberikan pengaruh besar bagi pembangunan Australia. Jalur-jalur ekspedisi mereka digunakan sebagai jalur perhubungan modern hingga saat ini. Dengan jumlah unta yang didatangkan ke
Australia mencapai 20.000 ekor antara 1860-1920, banyak dari hewan-hewan itu dibiarkan hidup liar setelah pemiliknya kembali ke kampung halaman. Peran paling penting adalah lahirnya komunitas muslim pertama lengkap dengan berdirinya masjid dan tradisi keagamaan, perayaan-perayaan di tanah Australia. Beberapa Muslim Afghan ini menikah dengan orang Aborigin maupun wanita kulit putih, menurunkan generasi campuran yang dinamis (Jones et al., 2010).

Peran besar para penunggang unta Muslim Australia ini kemudian justru melahirkan kecemburuan sosial. Sengketa tentang hak air di daerah gurun antara pospos unta dengan penggembala kulit putih mengemuka. Jaringan logistik yang dipegang the cameleers dianggap mengancam usaha kulit putih sehingga muncul "The Afghan Problems" atau permasalahan orang Afghan (Deen, 2006; Ross, 2000).

Usaha halal dipersoalkan sementara ketakutan akan dominasi imigran semakin tampak dengan terbitnya Immigration Restriction Act 1901 tentang pembatasan imigran kulit berwarna yang dikenal sebagai White Australian Policy (Restriction, 1901). Dengan aturan yang ketat dan menurunnya bisnis unta karena penggunaan kendaraan bermotor kehidupan muslim Afghan ini menjadi terdesak. Banyak yang beralih profesi namun menemui kegagalan karena di kota-kota ekonomi sudah dikuasai kelompok mayoritas. Banyak juga yang 
memilih meninggalkan Australia dari pada

seperti itu (Jones et al., 2010).

mendapatkan perlakuan diskriminatif
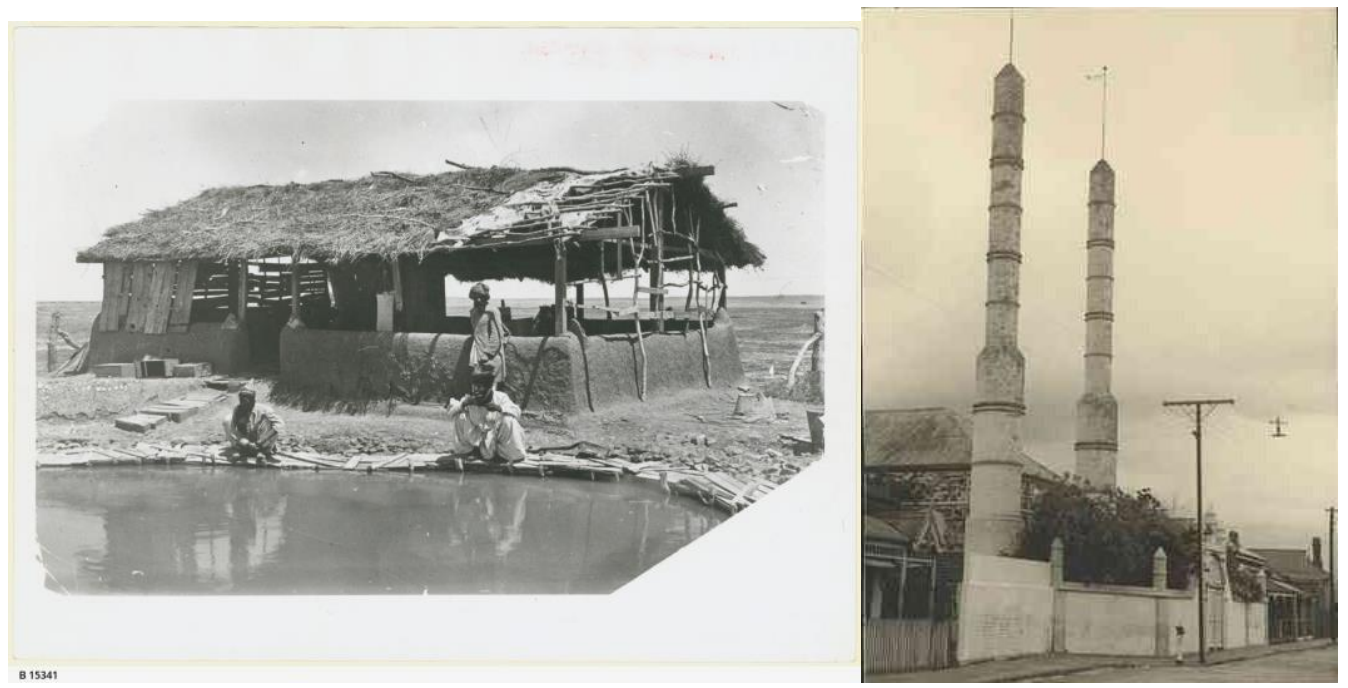

Gambar 2. Masjid Marree, masjid pertama di Australia (1861) (kiri) \& Masjid Adelaide (1888) (kanan) didirikan oleh komunitas Muslim the cameleers (https://collections.slsa.sa.gov.au/resource/B+15341 \& http://adelaidia.sa.gov.au/places/adelaide-mosque)

Galipoli. Perang Dunia I mendorong Australia berkonfrontasi dengan kekuatan muslim terbesar saat itu, Turki Utsmani. Dalam sentimen perang dimana pasukan Australia-Selandia Baru (ANZAC) mengalami kekalahan telak di Galipoli, sentimen anti-Turki mudah berubah menjadi sentimen anti-Muslim dan Islam (Yildiz, 2016). Simbolitas kekalahan dalam perang itu yang kemudian menjadi cikal bakal identitas nasional Australia dan Selandia Baru modern, senantiasa mendorong hubungan harmonis Turki dan Australia sebagai dua negara yang mendorong sekularisme ke arah liberalism. Namun, hal itu bukan berarti pandangan terhadap Islam. Australia pada saat itu menjadi simbol musuh negara Muslim bersama dengan Inggris sebagai negara penjajah, rasis, dan anti-Islam khususnya dalam narasi yang dibangun Presiden Turki saat ini (Yildiz, 2016).

Panggilan Jihad Khalifah di Istanbul rupanya tidak terlalu berhasil membangkitkan perlawanan kaum muslim di koloni-koloni Sekutu, namun gemanya sampai ke pedalaman Australia. Mullah Abdullah dan Muhammad Gul, dua orang penunggang unta pada Januari 1915 telah menembaki kereta pariwisata berisi 1200 orang, membunuh empat orang dan melukai tujuh lainnya (Jones et al., 2010; Rogan, 2016; Ross, 2000). Meskipun demikian, penyelidikan dari pertempuran Broken Hills di New South Wales itu didapati bahwa selain bersimpati pada perjuangan Kekhalifahan Turki, mereka juga diliputi sentimen diskriminasi sosial yang saat itu 
terjadi. Muhammad Gul memiliki latar belakang sebagai prajurit Turki yang terpantik emosinya saat Australia berperang melawan Utsmani. Sementara, Mullah Abdullah selain faktor jihad atas ajakan Gul, erat dengan usaha penyembelihan halal-nya yang baru saja ditutup karena dianggap tidak memenuhi standar kesehatan (Rogan, 2016).

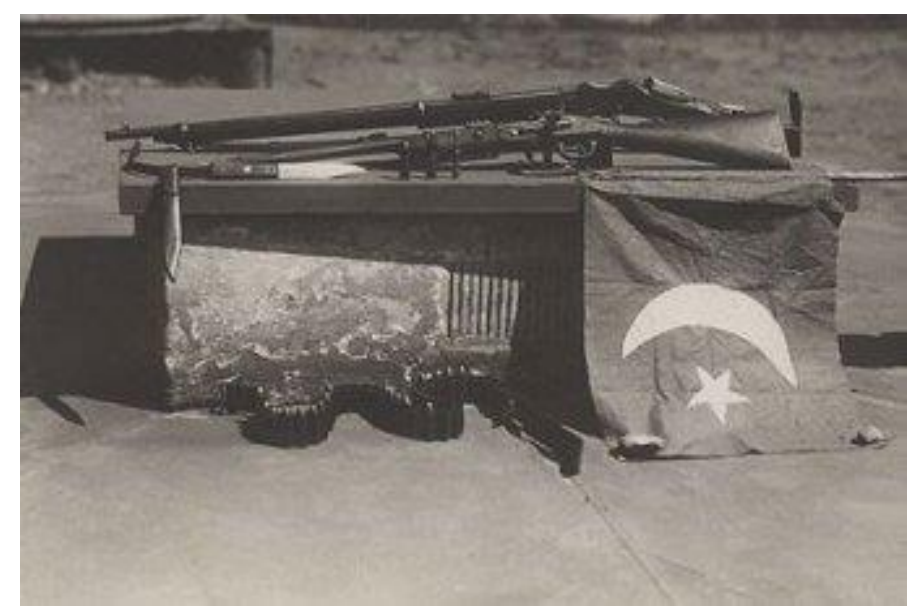

Gambar 3. Sisa-sisa peristiwa Broken Hills

(Jones \& Kenny, 2017: 149)

2. Rasisme dan Pertumbuhan Jumlah Muslim

\section{White Australian Policy (WAP).}

Demam emas yang melanda Australia Tenggara, Victoria dan New South Wales, memicu kehadiran pekerja migran China dan Pasifk yang dipekerjakan dengan bayaran murah di tambang-tambang. Pada puncaknya, populasi pekerja Asia ini mencapai lebih seperlima dari penduduk koloni New South Wales. Beberapa gesekan antar-ras juga terjadi di tambang-tambang. Berbeda dari orang-orang Makassar atau penunggang unta yang datang musiman atau pulang setelah kontrak mereka habis, para pekerja China banyak yang menetap setelah tiba di Australia dan terlibat dalam ekonomi lokal (Kabir, 2006). Meskipun ekonomi di kota-kota dan pedalaman menjadi lebih dinamis, kekhawatiran akan persaingan ekonomi membuat pemerintah merasa perlu serangkaian peraturan yang membatasi kehadiran etnis Asia-Pasifik di Australia. Kaum Muslim Afghan juga menjadi sasaran sikap anti-imigran ini bahkan direndahkan di bawah pendatang oriental (lihat. Edwards, 2018; Kabir, 2006).

Kebijakan pembatasan imigrasi tahun 1901 setelah pembentukan federasi dengan tegas menyatakan persyaratan warna kulit, hanya ras Eropa yang diperbolehkan bermigrasi ke Australia. Peraturan itu banyak menimbulkan efek surut, yaitu terjadi diskriminasi masif terhadap warga non-kulit yang telah tinggal di sana sebelum peraturan itu diterapkan, termasuk kepada warga asli Aborigin. Jumlah masyarakat muslim yang kecil akibat kebijakan WAP berlangsung sampai peiode 
pasca-perang dunia kedua. Ketika peraturan imigrasi tahun 1901 dicabut pada 1958 dan hak-hak hukum kaum Aborigin dikembalikan pada 1967, jumlah masyarakat non-Kristen hanya $0.8 \%$ dari sekitar 13 juta penduduk.

Jumlah ini meningkat menjadi $2 \%$ dalam sepuluh tahun berikutnya, 1981 dengan populasi muslim mencapai 0.5\% atau 77 ribu dari 14 juta jiwa. Peningkatan jumlah muslim cukup signifikan sejak 2000 berturut-turut komunitas muslim menyumbang $1.7 \%$; $2.2 \%$; dan $2.6 \%$ dalam sensus 2006, 2011, dan 2016 ("Religon in Australia," 2016). Sebagai masyarakat imigran, sebagian besar pertumbuhan penduduk Australia sejak tahun 1970-an disebabkan masuknya warga dari luar negara. Peningkatan jumlah komunitas muslim yang cukup signifikan juga didukung oleh trend yang sama.

Dalam sensus 1991, muslim kelahiran Lebanon mendominasi dengan 18\% dari jumlah populasi, diikuti Turki dengan 14.5\%. Sisanya berasal dari Eropa Timur (Bosnia, Albania), Afrika, dan Asia Selatan seperti India, Pakistan, dan Bangladesh. Angka ini berubah dalam sensus 2006 yang menunjukan dari 62\% komunitas muslim yang merupakan kelahiran di luar Australia, 9\% diantaranya berasal dari Lebanon dan 7\% Turki (Hassan \& Lester, 2018). Beragamnya afiliasi kultural dalam komunitas muslim Australia menyebabkan perbedaan cara hidup, cara pandang, bahkan dalam memahami dan mempraktekan Islam itu sendiri.

3. Australia Kontemporer dan Islam

Dengan perkembangan pascaberakhirnya kebijakan Australia Putih dimana banyak non-kulit putih bermigrasi ke sana, pemerintah mendorong semangat multikulturalisme di masyarakat. Kebijakan yang dipopulerkan di bawah pemerintahan Buruh PM Whitlam pada 1970-an untuk mempromosikan kehadiran migran nonkulit putih sebagai keniscayaan. Posisi ini didukung oleh baik Partai Buruh maupun Liberal dikembangkan oleh Frasser, Hawke, Keating, bahkan diikuti pengkiritik utamanya dari kalangan konservatif yang kemudian menjadi PM, John Howard (Koleth, 2011; Ross, 2000).

Kebijakan pro-minoritas yang dikembangkan pada 80-an dan kemudian 2000-an, kemudian berkembang menjadi semangat toleransi dan kesetaraan untuk mengungkapkan identitas kultural dan latar belakang etnis secara bebas termasuk afiliasi agama. Islam dan agama lain banyak diuntungkan dengan kebijakan ini, salah satunya bantuan-bantuan pemerintah dalam penyediaan rumah ibadah dan aktivitas sosial-keagamaan. Kampuskampus perguruan tinggi (hampir 90\% adalah milik pemerintah/ public university), mengadopsi kehadiran mahasiswa nonKristen dengan menyediakan ruang ibadah yang cukup representatif dan kebolehan menyelenggarakan Salat Jumat maupun 
acara-acara keagamaan di area kampus (Chowdhury, 2006; Possamai, Dunn, Hopkins, Worthington, \& Amin, 2016). Kebebasan mengekspresikan identi-tas personal khususnya bagi kaum minoritas di Australia, juga disikapi dengan kritik keras sebagian politisi dan aktivis "nasionalis".
Mereka menganggap kebijakan multikulturalisme pemerintah adalah naif dan melemahkan posisi Australia sebagai satu bangsa berbasiskan nilai Eropa-kulit putih. Kelompok yang muncul di kalangan partai Liberal Australia ini menekankan "integrasi" nasional dalam "nilai-nilai" keAustralia-an yang bersifat pro-Barat.

Tabel 1. Perkembangan Penduduk Muslim Australia 1981-2016

\begin{tabular}{cccc}
\hline Tahun & Jumlah Penduduk & Persentase Muslim & Jumlah Muslim \\
\hline 1981 & 14.576 .300 & 0.5 & 76.800 \\
1991 & 16.850 .300 & 0.9 & 147.500 \\
2001 & 18.769 .249 & 1.5 & 281.600 \\
2011 & 22.485 .300 & 2.2 & 476,290 \\
2016 & 23.401 .892 & 2.6 & 604,240 \\
\hline
\end{tabular}

*diolah dari data Badan Statistik Australia

(https://www.abs.gov.au/websitedbs/D3310114.nsf/Home/2016\%20Historical\%20Census\% 20Data)

Dalam kampanye untuk mem-Baratkan warga negara, kelompok ini seringkali menyerang komunitas Muslim sebagai ancaman kepada identitas Australia mereka (Kabir, 2006; Poynting \& Briskman, 2018). Dalam tahun 2000-an politik radikal kaum kanan yang lebih jelas memusuhi Islam semakin menguat. Berdirinya partai One Nation pada 1997 menyusul partai Australian First yang berdiri setahun sebelumnya, mendapatkan cukup suara dalam tahun-tahun terakhir. Pada pemiu 2019 lalu, dua wakilnya berhasil mendapatkan kursi senator (Visentin, 2019). Tokoh utamanya, Pauline Hanson, banyak menunjukan sikap anti-muslim, memicu kontroversi dengan menggunakan hijab dan burqa untuk mempromosikan sikap itu di Senat pada 2017. Dalam banyak kesempatan, ia juga banyak melemparkan tuduhan negatif kepada komunitas Muslim seperti sertifikasi halal, pelarangan pembangunan masjid, pengawasan lebih ketat pada komunitas muslim, dan menyebut Muslim bertanggung jawab penuh pada terorisme di Australia (Poynting \& Briskman, 2018; Rashid, 2011). Pidato perdananya pasca terpilih di Senat, dengan terbuka ia mengungkapkan "Islam cannot have a significant presence in Australia if we are to live in an open, secular and cohesive society". "Islam tidak boleh dibiarkan ada di Australia jika kita ingin hidup terbuka, sekuler, dan guyub". (Hanson, 2016). Ada juga politisi rasis dan anti-Muslim lain seperti Frasser Anning 
(mantan anggota partai One Nation) yang justru menyalahkan komunitas Muslim dalam serangan teror di Christchurch, Selandia Baru dan terkenal karena serangan telur busuk dari seorang remaja yang kesal karena pernyataannya (Association, 2019).

Di tataran masyarakat, kehadiran politisi-politisi garis keras seperti Hanson dan Anning juga mendorong sikap radikal anti-imigran, khususnya anti-Islam. Meskipun kebanyakan serangan kepada komunitas Muslim lebih banyak berupa serangan psikologis melalui ujaran, hasutan, dan hinaan verbal, serangan fisik juga beberapa kali terjadi. Pandangan curiga dan sebelah mata mudah ditemukan bagi orangorang dengan ciri khusus, berjanggut, berjilbab, atau wajah Timur Tengah. Seorang muslimah diserang, didorong, jatuh hingga patah tangannya oleh sekelompok pemuda di sebuah pusat pertokoan kota Melbourne pada 2014.

Mereka meneriakinya “...muslim tidak boleh ada di sini" (Millen, 2014). Kasus itu berulang pada 2018 lalu, ketika seorang mahasiswi Indonesia diserang oleh beberapa orang karena berjilbab di pusat ibukota Canberra yang selama ini dikenal terbuka dan toleran pada kaum minoritas (Whyte, 2019). Mushala kampus juga menjadi target kebencian seperti pembuangan sampah di Universitas Sydney dan kasus pembuangan kepala babi di Universitas Western Australia (Kembrey, 2016; "Pig's head left near WA uni Muslim room," 2015). Persentase populasi Muslim di Australia sebenarnya tidak terlalu besar dibanding kelompok agama lainnya, bahkan mereka yang mengaku tidak beragama (30\% pada 2016). Secara demografis, pertumbuhan penduduk berkulit kuning seperti China dan Vietnam dengan Buddhanya atau India dengan agama Hindu jauh lebih pesat dari pertumbuhan pendatang muslim baru-baru ini (Australian Bureau of Statistics, 2016).

Namun, kesan ancaman atas komunitas Muslim menguat dan memicu sentimen anti-Islam bagi sebagian kalangan. Memang, aktivis atau politisi anti-Islam rata-rata juga anti-kebijakan pro-imigran dan itu berlaku kepada hampir semua warga non-kulit putih, China, India, Afrika, dan lain-lain. Meskipun demikian, kelompok Muslim mengalami alienasi yang paling parah, salah satunya disebabkan politik pemerintah antara akhir 1990-an sampai saat ini (Edwards, 2018).

Dalam konteks politik nasional Australia sendiri, komunitas muslim dihadapkan pada pilihan-pilihan yang cukup sulit. Dua kelompok besar yang diwakili oleh kaum kanan Liberal-Nasional dan di sisi lain kaum kiri Partai Buruh, yang mendominasi percaturan politik di negeri itu selama sejarah federasi masing-masing memunculkan dilema tersendiri dalam politik komunitas muslim. Selama ini prinsip egalitarian-sosialis dan kebebasan sosial "a fair go" partai tersebut banyak 
menguntungkan bagi golongan minoritas termasuk Muslim dalam kebijakan imigrasi, multikulutralisme, bahkan kesempatan politik menjadi anggota parlemen atau majelis daerah (Al-Momani, Dados, Maddox, \& Wise, 2010). Di sisi lain kebijakan sosial yang liberal itu juga cukup menyulitkan prinsip Muslim secara umum seperti dalam isu legalisasi LGBT dalam Marriage Equality. Meskipun demikian, platform partai Liberal-Nasional, termasuk tendensi antiimigran, pro-supremasi kulit putih, dan kebijakan pro-AS, lebih menyudutkan posisi Muslim (Al-Momani et al., 2010; Rashid, 2011), walaupun dalam isu-isu sosial, kebijakan konservatif mereka lebih sejalan dengan keyakinan Muslim contohnya dalam kasus legalisasi LGBT (Smith, 2019). Aliansi keamanan Amerika Serikat- AustraliaSelandia Baru (ANZUS) yang terjalin sejak berakhirnya Perang Dunia Kedua, ikut berperan besar dalam memojokan posisi komunitas Muslim di negara itu.

Perang Afghanistan adalah awal keterlibatan Australia dalam kontak langsung terhadap Islam dunia. Sebagai bagian dari aliansi anti-Soviet, saat itu Australia berada dalam kubu yang sama dengan kaum Taliban dan Mujahidin melawan pemerintahan Komunisme. Kontak itu dalam masa 1990-an berubah menjadi permusuhan karena posisi AS yang berlawanan dengan pemerintahan Taliban, memperpanjang konflik di Negara itu dan semakin memperkuat citra Barat yang anti-
Islam dan perang melawan Islam (Koleth, 2011; Rashid, 2011). Perang Teluk 1991 juga dukungan atas Invasi Iraq 2003 pascaserangan 11 September, membawa Australia yang beraliansi dengan AS dalam permusuhan yang sama di Timur Tengah. Bagaimanapun juga, isu war against terror yang dikampanyekan Amerika Serikat banyak bersinggungan dengan tuduhan umum bahwa Islam identik dengan terorisme.

Dampak negatif dari kebijakan pemerintah Australia dalam isu terorisme ini diakui oleh pemerintah sendiri dalam investigasinya pada 2010 menyatakan “...some media and political commentary sought to link terrorism with Islam", “...sebagian media dan komentar politik menghubung-hubungkan terorisme dengan Islam...”, sebagai dampaknya, “...many Arab and Muslim Australians, as well as some other minority groups, were subjected to heightened acts of prejudice, vilification and violence, that left them feeling isolated and fearful".

"Banyak orang Arab dan Muslim Australia, begitu juga sebagian kaum minoritas, telah menjadi sasaran kecurigaan, ujaran kebencian, dan kekerasan, yang menyebabkan mereka merasa terasing dan ketakutan"(Koleth, 2011). Kesan umum warga Australia terhadap Islam secara umum cenderung positif. Dalam sebuah survey nasional khusus membahas isu Islamofobia dan 
terorisme tahun 2015, penelitian dari Universitas South Australia menunjukan hanya $10 \%$ saja dari penduduk yang dianggap memiliki Islamofobia. Hampir 79 persen menyatakan hak-hak bekerja bagi Muslim harus dilindungi termasuk di areaarea publik (dalam konteks serangan teror). Adapun $86 \%$ di antara responen merasa nyaman ketika berkomunikasi dengan komunitas Muslim.

Sementara itu, $75 \%$ menentang pengasingan sosial komunitas Muslim dan mau agar mereka diterima dalam masyarakat seperti biasa (Hassan, 2015; Hassan \& Lester, 2018). Meskipun cukup meggembirakan, laporan ini juga menggarisbawahi relasi sosial komunitas Muslim dalam masyarakat. Ada 24\% responden menolak pendirian masjid; 19\% mengaku tidak ingin bertetangga dengan Muslim.

Lebih menarik lagi, sebanyak 52\% responden yang mengaku berhubungan secara rutin dengan komunitas Muslim justru merasa terancam oleh terorisme dibanding 48\% mereka yang tidak menjalin kontak sama sekali. Dalam kesimpulannya, penelitian dari UniSA menyebutkan bahwa secara umum Islamofobia masih rendah meskipun eksis dipengaruhi oleh faktor pendidikan, ekonomi, dan afiliasi politik. Kedua, bahwa komunitas Muslim relatif berjarak secara sosial dengan komunitas keagamaan lain dan posisinya terpengaruh oleh sentimen terorisme global (Hassan,
2015). Kesan eksklusivisme sosial atau keterhambatan menjalin relasi masyarakat yang kuat antara komunitas Muslim dan lainnya di Australia menurut Khawaja \& Khawaja (2016) justru disebabkan diskriminasi yang mereka dapatkan. Media telah membesar-besarkan segelintir Muslim yang berperilaku buruk sehingga mengesankannya secara umum.

Pada akhirnya masyarakat merespon dengan menjauhkan anggota komunitas Muslim dari pekerjaan, hak-hak publik, dan menghindar dari kontak sosial. Kebanyakan pengetahuan bias dari media masa itu diterima tanpa sanggahan. Padahal, pengetahuan publik tentang Islam sendiri masih lemah dan sentimen yang negatif tidak membuat mereka mencari tahu lebih jauh tentangnya (Mansouri \& Vergani, 2018).

Meskipun demikian, penelitian doktoral Abdi Hersi (2016) menemukan bahwa memang konsep integrasi sosial Muslim Australia secara umum lebih kepada integrasi dalam aspek sosio-ekonomi bukan budaya. Kompromi bisa dilakukan sebatas hukum agama memperbolehkan. Namun, dalam prakteknya hal ini seringkali juga berupa bentuk-bentuk budaya asal seseorang yang terasosiasi dengan Islam meskipun bukan merupakan bagian dari garis merah ajaran Islam sendiri (syariah). Hal ini yang menjadi ketakutan atas "kenyataan" Islam (visibility) yang 
mendominasi masyarakat lainnya (Hersi, 2016; Mansouri \& Vergani, 2018).

\section{Kesimpulan}

Islam meski telah hadir di Australia sebelum kedatangan bangsa Eropa, tidak memiliki akar yang kuat. Mereka baru muncul sebagai komunitas permanen sekitar satu setengah abad yang lalu dengan hadrinya para penunggang unta dari Asia Selatan. Kehadiran masyarakat itu segera melahirkan gesekan sosial yang berujung pada lemahnya ikatan antar komunitas. Dengan demikian sejak awal masyarakat muslim sudah menjadi alien dalam masyarakat Australia yang didominasi bangsa Eropa. Dalam masa yang singkat pertumbuhan penduduk diinterupsi oleh kebijakan migrasi rasial dan baru pada era 1970-an mulai kembali meningkat.

Dalam struktur masyarakat yang berubah serba cepat itu terjadi kegamangan budaya maupun keterancaman sosial (social and cultural anxiety) di kalangan orang Australia berlatar belakang Eropa mungkin awalnya kepada seluruh pendatang Asia termasuk China dan India, namun berkembang menjadi ketakutan atau fobia. Pada dasarnya masyarakat Australia terbuka pada semua kultur, latar belakang, dan afiliasi agama termasuk Islam. Akibat dari kampanye negatif media, politik pemerintah yang pro-Amerika dalam war on terror, juga kampanye buruk ekstrimis antiIslam, membuat prasangka dan stigma negatif berkembang. Untuk kepentingan mereka, segelintir politisi menggunakan isuisu sensitif imigrasi dan Islamofobia sebagai alat mendulang suara, sesuatu yang umum terjadi; politik menggunakan isu-isu rasis, tendensius dan anti-minoritas, di semua negara di dunia.

Umat Islam di Australia juga terkesan mengalami keterbatasan jangkauan integrasi khususnya menghadapi isu-isu sosial yang dianggap bertentangan dengan nilai-nilai jurisprudensi Islam. Kebijakan multikulturalisme pemerintah di satu sisi memberi ruang setiap komunitas untuk berkembang dengan identitasnya masing-masing, namun juga memicu fragmentasi sosial yang cukup terasa. Antar komunitas bergerak sendiri-sendiri seringkali tanpa dialog dan komunikasi yang baik, apalagi dalam stigma negatif yang sudah sejak awal terjadi.

Simbolitas kultural dan asal-usul personal lebih kuat dalam menunjukan keIslam-an seperti dalam arsitektur, relasi keluarga, dan cara berpenampilan sehingga tampak asing di tengah lingkungan sekitar. Sementara itu, koneksi global masyarakat Islam yang beragam di Australia menyebabkan berbagai paham mudah masuk, termasuk interpretasi Islam yang puritan mengarah ke radikal. Memang istilah "radikal" ini juga mengandung tafsiran subjektif, namun agaknya jelas terlihat terdapat komponen kecil dalam masyarakat muslim Australia yang memang 
anti-dialog, mengisolasi diri, dan mudah menyalahkan keadaan, bahkan kepada kalangan umat Islam sendiri. Hal ini yang memicu keterlibatan warga negara Australia Muslim dalam gerakan terror global seperti ISIS, Al-Qaeda, atau terorisme individual di dalam negeri.

Studi ini masih terkendala oleh keterbatasan dalam sumber-sumber sezaman dan terbatas pada deskripsi historis daripada interpretasi yang aktual. Penelitian lebih lanjut dapat dilakukan dengan memasukan aspek-aspek ilmu bantu seperti politik, studi media, dan kajian kebudayaan dalam menilai posisi Islam dan umat Muslim di Australia secara lebih komprehensif dan mendalam.

\section{Daftar Pustaka}

Al-Momani, K., Dados, N., Maddox, M., \& Wise, A. (2010). Political Participation of Muslims in Australia: Final Report June 2010.

Association, P. (2019). Fury as Australian senator blames Christchurch attack on Muslim immigration. The Guardian. Retrieved from https://www.the guardian.com/world/2019/mar/15/au stralian-senator-fraser-anningcriticised-blaming-new-zealand-attackon-muslim-immigration

Australian Bureau of Statistics. (2016). Cultural diversity in Australia - 2016 census data summary. 2016 Census Data, 1-2. Retrieved from https://www.abs.gov.au/ausstats/abs @.nsf/Lookup/bySubject/2071.0 201 6 Main Features $\sim$ Cultural Diversity Data Summary 30

Bazian, H. (2018). Islamophobia, "Clash of civilizations", and forging a post-cold war order! Religions, 9(9), 1-13. https://doi.org/10.3390/rel9090282
Blaxland, J. (2019). A Geostrategic SWOT Analysis for Australia. The Centre of Gravity Series, 49(June), 1-20.

Briskman, L., \& Latham, S. (2017). Muslims at the Australian periphery. Coolabah, (21), 33-46. https://doi.org/10.1344/ co20172133-46

Chowdhury, N. (2006). Presenting Islam: The role of Australia-Based Muslim Student Associations. Journal of Muslim Minority Affairs, 26(2), 205-224. https://doi.org/10.1080/1360200060 0937705

Deen, H. (2006). Excavating the Past: Australian Muslims. 0-4.

Edwards, R. (2018). Muslim Community Organisations and Leadership in Australia Submitted by. (August), 0-1.

Ganter, R. (2013). Histories with Traction: Macassan Contact in the Framework of Muslim Australian history. In M. Clark \& S. K. May (Eds.), Macassan History and Heritage: Journeys, Encounters and Influences (pp. 55-68). https://doi.org/ 10.22459/MHH.06.2013

Ghauri, M. J., Yousaf, Z., \& Iqbal, Z. (2017). Discourses on Islam and Muslims in Australia. Journal of Political Studies, 24(641). Retrieved from http://pu.edu.pk/images/journal/pols /pdf-files/23_24_2_17.pdf

Hanson, P. (2016, September 15). Transcript: Pauline Hanson's 2016 maiden speech to the Senate. ABC News. Retrieved from https://www.abc.net.au /news/2016-09-15/pauline-hansonmaiden-speech-2016/7847136

Hassan, R. (2015). Islamophobia, social distance and fear of terrorism in Australia.

Hassan, R., \& Lester, L. (2018). Australian Muslims: The Challenge of Islamphobia and social distance. Retrieved from https://www.unisa.edu.au/contentasse ts/4f85e84d01014997a99bb4f89ba32 488/australian-muslims-final-reportweb-nov-26.pdf

Hersi, A. M. (2016). Australian Muslims Conceptions of Integration. (April).

Jones, P., Kenny, A., \& Museum, S. A. (2010). 
Australia's Muslim Cameleers: Pioneers of the Inland, 1860s-1930s.

Kabir, N. (2006). Muslims in a "White Australia": Colour or Religion? Immigrants and Minorities, 24(2), 193223. https://doi.org/10.1080/0261928 0600863671

Kembrey, M. (2016). Islamic prayer room at Sydney University reportedly trashed. The Sydney Morning Herald. Retrieved from https://www.smh.com.au/ national/nsw/islamic-prayer-room-atsydney-university-reportedly-trashed20160224-gn2fa6.html

Khawaja, N. G., \& Khawaja, S. (2016). Acculturative issues of muslims in Australia. Journal of Muslim Mental Health, 10(2), 43-53. https://doi.org/ 10.3998/jmmh.10381607.0010.203

Koleth, E. (2011). Multiculturalism: a review of Australian policy statements and recent debates in Australia and overseas. Retrieved from Research Paper no. 6 2010-11 website: https://www.aph.gov.au/About_Parlia ment/Parliamentary_Departments/Parl iamentary_Library/pubs/rp/rp1011/1 1rp06

Kuntowijoyo. (2005). Pengantar Ilmu Sejarah. Bandung: Penerbit Bentang.

Macknight, C. (2013). Studying Trepangers. In M. Clark \& S. K. May (Eds.), Macassan History and Heritage: Journeys, Encounters and Influences (pp. 19-40). https://doi.org/10.22459/MHH.06.201 3

Mansouri, F., \& Vergani, M. (2018). Intercultural contact, knowledge of Islam, and prejudice against muslims in Australia. International Journal of Intercultural Relations, 66(June 2017), 85-94. https://doi.org/10.1016/j.ijint rel.2018.07.001

Millen, V. (2014). Muslim woman's arm broken in racist attack. The Age. Retrieved from https://www.theage. com.au/national/victoria/muslimwomans-arm-broken-in-racist-attack20141027-11cdat.html

Pig's head left near WA uni Muslim room.
(2015). SBS News. Retrieved from https://www.sbs.com.au/news/pig-shead-left-near-wa-uni-muslim-room

Possamai, A., Dunn, K., Hopkins, P., Worthington, L., \& Amin, F. (2016). Muslim students' cultural and religious experiences in city, suburban and regional university campuses in NSW, Australia. Journal of Higher Education Policy and Management, 38(6), 637648. https://doi.org/10.1080/13600 80X.2016.1211950

Poynting, S., \& Briskman, L. (2018). Islamophobia in Australia: From farright deplorables to Respectable Liberals. Social Sciences, 7(11), 1-17. https://doi.org/10.3390/socsci711021 3

Rashid, T. (2011). Australia's War on Terrorism: Impact on Australian Muslim Communities. In Babacan, Alperhan, Tahiri, \& Hussein (Eds.), Counter Terrorism and Social Cohesion (First, pp. 61-80). Cambridge Scholars Publishing.

Religon in Australia. (2016). Retrieved from Australian Bureau of Statistic website: https://www.abs.gov.au/ausstats/abs @.nsf/Lookup/bySubject/2071.0 201 $6 \sim$ Main Features $\sim$ Religion Data Summary 70

Restriction, I. (1901). Immigration Restriction Act 1901 (Cth) as made. https://doi.org/10.2307/3035180

Rogan, E. (2016). Rival jihads: Islam and the Great War in the Middle East, 19141918. Journal of the British Academy, 4(January), 1-20. https://doi.org/10.58 $71 / \mathrm{jba} / 004.001$

Roose, J. M., \& Roose, J. M. (2016). Muslims in Australia. Political Islam and Masculinity, 33-49. https://doi.org/10. 1007/978-1-137-52230-6_3

Ross, J. (2000). Chronicle of Australia. Ringwood, VIC: Viking Penguin Books Australia Ltd.

Sjamsuddin, H. (2007). Metodologi Sejarah. Yogyakarta: Ombak.

Smith, A. (2019). Christian group rally with Muslims targeting "godless" ALP ahead 
of election. The Sydney Morning Herald. Retrieved from https://www.smh.com .au/federal-election-2019/christiangroup-rally-with-muslims-targetinggodless-alp-ahead-of-election20190506-p51kkh.html

Thomas, P. (2013). Interpreting the Macassans: Language exchange in historical encounters. In M. Clark \& S. K. May (Eds.), Macassan History and Heritage: Journeys, Encounters and Influences (pp. 69-94). https://doi.org /10.22459/MHH.06.2013

Visentin, L. (2019, April 15). One Nation wins two upper house seats in the NSW Parliament. The Sydney Morning Herald. Retrieved from https://www.smh.com. $\mathrm{au} / \mathrm{politics} / \mathrm{nsw} / \mathrm{one}$-nation-wins-twoupper-house-seats-in-the-nswparliament-20190415-p51e7i.html

Whyte, S. (2019). Two Indonesian students attacked at Canberra Centre. The Canberra Times. Retrieved from https://www.canberratimes.com.au/st ory/5995378/two-indonesian-

students-attacked-at-canberra-centre/

Yildiz, H. (2016). Gallipoli : A Sacred Site The Power of Political Language, Myths and Monuments in the Re / making of National History Gallipoli : A Sacred Site The Power of Political Language, Myths and Monuments in the Re / making of National History Supervisor: St. (September). 